\title{
The record of early-formed heterogeneities preserved in the modern day mantle
}

\author{
S. MUKhOPADHYAY ${ }^{1}$, C. D. WiLliams ${ }^{1}$, R. PARAI ${ }^{2}$, \\ J. M. TUCKER ${ }^{3}$, M. L. RUDOLPH ${ }^{1}$ AND B. \\ ROMANOWICZ ${ }^{4,5,6}$ \\ ${ }^{1}$ Department of Earth and Planetary Sciences, Univ of \\ Califoria Davis, Davis, CA, USA; sujoy@ucdavis.edu \\ ${ }^{2}$ Department of Earth and Planetary Sciences, Univ of \\ Washington St. Louis, MO, USA \\ ${ }^{3}$ Department of Terrestrial Magnetism, Carnegie Instutition \\ for Science, Washington DC, USA \\ ${ }^{4}$ Department of Earth and Planetary Sciences, Univ of \\ Califoria Berkeley, Berkeley, CA, USA \\ ${ }^{5}$ College de France, Paris, France \\ ${ }^{6}$ Institut de Physique du Globe de Paris, Paris, France
}

The geochemistry of mantle-derived lavas requires longterm differences be preserved between different regions of the Earth's mantle. In particular, the primoridal noble gas isotopes of neon, the short-lived ${ }^{182} \mathrm{Hf}^{182} \mathrm{~W}$ system, and the short lived I-Pu-Xe system have left a record of events that occurred during Earth's earliest history in modern day rocks. Reading this record has required developing higher precision measurement techniques, which have provided a wealth of new information. These include a record of the growth phase of proto-Earth in the presence of the nebula, a memory of giant impacts during accretion, preservation of mantle heterogeneities since $4.5 \mathrm{Ga}$, and core-mantle interactions.

In parallel with the improvements in measurement techniques, there have been significant developments in integrating geochemical observations of mantle-derived lavas with seismic observations and mantle flow models. These approaches highlight how variations in the isotopic compositions of mantle-derived lavas are related to temperature variations in the Earth's interior, where the ancient reservoir(s) might be located in the deep mantle, when they might have formed, and the nature of their interactions with the rest of the mantle.

Realizing the full potential of the short-lived systems for unlocking secrets of the early Earth will require a careful charcterization of Hf-W and I-Pu-Xe from the same samples along with better constraints on metal-silicate partitioning for $\mathrm{I}$ and Xe. Iodine appears to become siderophile at high pressures but the poorly-characterized high-pressure partitioning for Xe means core-mantle interactions could impart either a low $\mathrm{I} / \mathrm{Xe}$ ratio or high $\mathrm{I} / \mathrm{Xe}$ ratio to the mantle. 